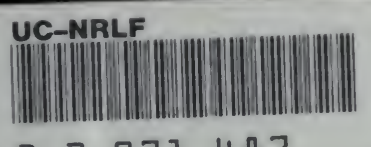

B $307148 ?$ 


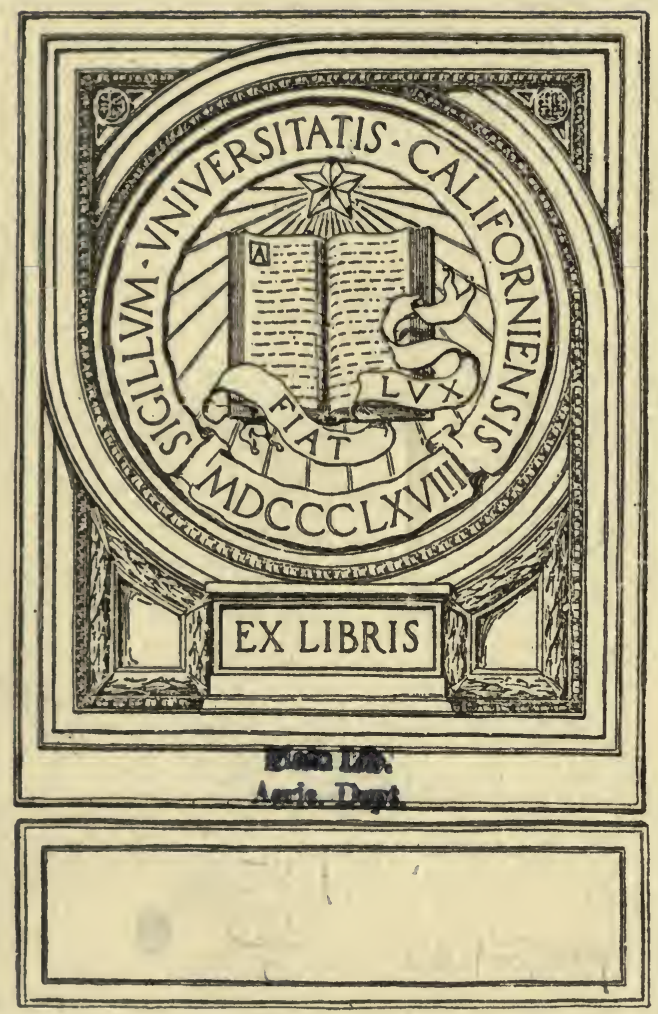



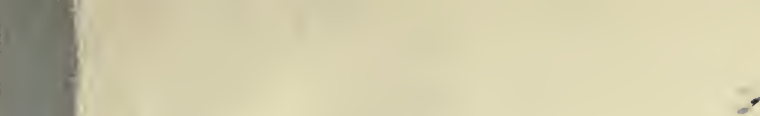

$\therefore \quad \therefore 7$ 
Digitized by the Internet Archive in 2007 with funding from Microsoft Corporation 


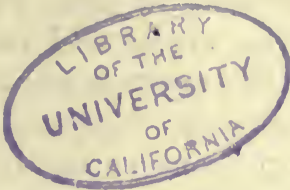 \\ United States Department of Agriculture.}

BUREAU OF CHEMISTRY-Circular No. $x 8$.

H. W. WILEY, Chief of Bureau.

\section{SUGGESTIONS TO IMPORTERS OF FOOD PRODUCTS.}

The act making appropriations for the Department of Agriculture for the fiscal year ending June 30, 1905, contains the following provision relating to the inspection of imported food products:

To investigate the adulteration, false labeling, or false branding of foods, drugs, beverages, condiments, and ingredients of such articles, when deemed by the Secretary of Agriculture advisable; and the Secretary of Agriculture, whenever he has reason to believe that such articles are being imported from foreign countries which are dangerous to the health of the people of the United States, or which shall be falsely labeled or branded either as to their contents or as to the place of their manufacture or production, shall make a request upon the Secretary of the Treasury for samples from original packages of such articles for inspection and analysis; and the Secretary of the Treasury is hereby authorized to open such original packages and deliver specimens to the Secretary of Agriculture for the purpose mentioned, giving notice to the owner or consignee of such articles who may be present and have the right to introduce testimony; and the Secretary of the Treasury shall refuse delivery to the consignee of any such goods which the Secretary of Agriculture reports to him to have been inspected and analyzed and found to be dangerous to health, or falsely labeled or branded, either as to their contents or as to the place of their manufacture or production, or which are forbidden entry or to be sold, or are restricted in sale in the countries in which they are made or from which they are exported.

In order to facilitate the execution of this law and to avoid any unnecessary delay in the inspection of products on arrival, the attention of importers is called to the following suggestions:

1. The inspection of food products includes foods, beverages and condiments, and ingredients of such articles.

2. The inspection, under the language of the law, relates to the following points:

(a) To ascertain if the imported products are injurious to health.

(b) If they be falsely branded or labeled in regard to the contents of the packages.

(c) If they be falsely branded or labeled as to the place of manufacture or production. 
(d) If they be forbidden entry to or are restricted in sale in the country in which they are made or from which they are exported.

3. A food product, in the absence of contrary judicial interpretation, will be deemed by the Department of Agriculture to be adulterated-

(a) If any valuable ingredient naturally present therein has been extracted.

(b) If a less valuable ingredient has been substituted therefor.

(c) If it be colored, powdered, or polished, with intent to deceive, or to make the article appear of a better quality than it really is.

$(d)$ If it be a substitute for or imitation of a genuine article and offered under the name of that article.

4. Products will be deemed injurious to health in the absence of contrary judicial determination-

(a) If any substance, with the exception of the long-used, wellknown condimental substances, viz, common salt, spices, sugar (sucrose or saccharose), wood smoke, and vinegar, be added thereto for preserving, coloring, or other purposes, which is injurious to health, either as determined by actual experimental evidence or in the predominating opinion of health officers, hygienists, and physiological chemists.

(b) If the products be decomposed, filthy, decayed, or in any unfit condition for human consumption.

5. Products will be considered by the Department as misbranded in the absence of contrary judicial determination-

(a) If any false name or property be assigned thereto in the label, directly or by implication.

(b) If any false statement be contained in the label relating to the place of manufacture or production of the contents of the package directly or by implication.

(c) If they are not of the nature, substance, and quality commonly associated with the name under which they are sold or offered for sale.

6. Food products will also be excluded from entry into the United States if they are of a character or kind forbidden entry in the country where they are manufactured or from which they are exported.

7. Food products will also be excluded from the United States if they are forbidden to be sold or are restricted in sale in the countries in which they are manufactured or from which they are exported.

ILLUSTRATIONS.

Until further notice, or until the matter shall have been determined by judicial decisions, or until the permanent standards for the products mentioned have been established by proclamation, the Department submits the following illustrations for the guidance of importers, as an 
index to the action of the Department in cases where the products hereinafter mentioned, and like products, are offered for import:

1. Wine bearing a classed name, that is, brands of wine of high grade recognized by law and by commercial usage, must be true to name; for instance a wine bearing the name Chateau Larose must be wine coming from the vineyard covered by that appellation and no other. Importers should be ready to furnish certificates, when asked for, of conformity of the wine to the label used. Stretched wine, that is, wine containing a part of the original wine, or a similar wine from a different vineyard, should not be labeled with the name of a true, classed wine.

2. Wine containing sulphurous acid in amount greater than that first mentioned below, added as a preservative or for other purposes, should carry upon the label "Preserved with sulphurous acid," and the declaration accompanying it should state approximately the quantity of sulphurous acid present. The admission of wines containing not more than 200 milligrams of sulpharous acid per liter, added in the usual cellar treatment, of which not more than 20 milligrams shall be free acid, is permissible without notification. Wines containing more than 350 milligrams per liter of sulphurous acid should not be offered for importation under any conditions.

3. Sugar wines are wines which are made partly by the addition of sugar to the must or otherwise previous to fermentation, and should bear upon the label "Sugar wines," or some similar legend, and the quantity of sugar employed in their manufacture should be stated in the declaration before the consul.

4. Mixed wines, that is blended wines, should not bear the name of the vineyard from which a part of the mixture is made, unless the label plainly indicates that it is a blend or mixture with other wines. If wine from any other country than that where the mixture is made, or from which it is exported, be employed, a statement to that effect should be found upon the label and in the declaration. Wines, sulphured wines, sugar wines, and mixed wines should not contain over 14 volume per cent of alcohol.

5. Fortified wines, that is, wines to which additional alcohol has been added, under the law of the United States regulating fortification of wines, should contain no added alcohol except that derived from the distillation of wine, and the brandy so used should be properly aged in oak casks in order to be free from injurious compounds such as fusel oils, etc. Raw brandy made from the lees, pomace, and refuse of the winery, and containing excessive quantities of fusel oil and other injurious ingredients, should not be used in the fortification of wines imported into the United States. Importers are requested to secure such information from their agents abroad as may enable them to certify to the character of the brandy used for fortification when any doubt exists. 
6. Brandy (potable brandy) is the distillate from wine, properly aged by storage in wood to eliminate the greater part of the fusel oils, etc., which may be present. Brandy should contain not less than 45 nor more than 55 volume per cent of alcohol and not more than 0.25 per cent of total solids (extract). The content of fusel oils should not exceed 0.25 per cent. Brandy should not be mixed with alcohol from any other source than that of distilled wine. The distillate from the lees, pomace, and refuse of the winery is not entitled to bear the term "brandy" in the potable sense. "Cognac" is only admitted as a name in the case of brandies made in Cognac from wines grown and manufactured there. No artificial color other than that derived from the wood in which they are aged is admitted in brandies.

7. Whisky is the distilled product of fermented cereal grains, properly aged in wood in order to remove the greater part of the fusel oils, etc., produced during the distillation. Whisky should not contain less than 45 nor more than 55 volume per cent of alcohol and not more than 0.25 per cent of total solids (extract). The content of fusel oils should not exceed 0.25 per cent. No artificial color other than that derived from the wood in which it is stored is admitted in whisky. Blended whisky is whisky made of two or more whiskies. Compound or " rectified" whisky is whisky made with or without the use of some whisky from neutral, cologne or silent spirits, that is, pure alcohol, to which artificial flavoring and coloring matters may be added. Such whiskies should be plainly branded on the label "Compound" or "Compounded," even if containing a percentage of pure whisky.

8. Beer is the fermented product of cereal grains, the starch of which has been converted into sugar by malt or malting, and to which an infusion of hops has been added.

9. Fruit compounds, such as jams, jellies, marmalades, etc., are preparations made from pure fruits or fruit juices, with the addition of sugar. The presence of artificial coloring matter, flavors, glucose, preservatives, and other added substances is not admitted for the pure products, and when used the fact should be plainly indicated in the English language upon the label. These bodies should not bear the name of any one fruit alone if they are made from mixtures of fruit or fruit juices.

10. Sausage is the comminuted edible meat of healthy slaughtered animals, commonly used as food, mixed with salt and condimental substances. The packages should bear the certificate of an official inspector as to purity, and if pork, that it is free from trichinæ. The addition of preservatives should be plainly stated upon the label, and if these preservatives be deemed injurious to health, such sausages can not be admitted. Coloring matter's when used are under similar restrictions.

11. Salad (edible) oils shall bear the name of the substance from 
which they are made, namely, olive, cotton seed, sesame, peanut, etc. The designation "salad oil" is not sufficient. If mixtures, this fact should be plainly stated upon the label, in harmony with the principles already laid down. The ingredients of a mixed oil should have their origin (country) named upon the label in order to conform with the provisions of the law.

12. Vinegar should contain not less than 4 per cent of acetic acid. The kind of vinegar should be named upon the label, namely, cider vinegar, wine vinegar, malt vinegar, spirit vinegar-meaning vinegar derived from the acetous fermentation of cider, wine, malt liquors, or distilled spirits, respectively. Any added coloring or other foreign matter should be noted upon the label and in the declaration.

13. Labeling: If more than one article be present in a.food product, the name of one of the substances alone is not deemed to be a sufficient label. If peas or beans have a portion of copper the label should state that fact. The various natural constituents of a food product need not be noted, nor the presence of the usual condimentary substances employed in foods, viz, sugar, salt, spices, vinegar, and wood smoke. The term "sugar" is used in its usual signification, viz, sugar made from sugar cane, sugar beets, maple trees, sorghum, etc. When sugars are made by the artificial hydrolysis of starch, by an acid or malt, that fact should be noted on the label by the term "glucose," or starch sugar. "Grape sugar" is not admitted as a correct term for such products.

\section{GENERAL STATEMENT.}

The above specific illustrations indicate the position of the Department in regard to the general character of food products which may be imported without question.

The importer will do well to require his agents in foreign countries to carefully comply with the general principles set forth. In a few words they may be summarized as follows: Freedom from deleterious substances, notification of added foreign substances, truthfulness in labeling.

The standards of purity for food products, which have been fixed by the Secretary of Agriculture in harmony with existing law, are given in the following pages and are applicable to imported foods, which should conform to these established standards.

$$
\begin{gathered}
\text { H. W. WHLEY, } \\
\text { Chief, Bureau of Chemistry. }
\end{gathered}
$$

Approved:

Willis L. Moore, Acting Secretary of Agriculture.

Wasinngton, D. C., August 6, 1904. 


\section{STANDARDS OF PURITY FOR FOOD PRODUCTS. ${ }^{a}$}

Whereas the Congress of the United States by an act approved June 3, 1902, authorized the Secretary of Agriculture to establish standards of purity for food products; and

Whereas he was empowered by this act to consult with the committee on food standards of the Association of Official Agricultural Chemists and other experts in determining these standards; and

Whereas he has in accordance with the provisions of the act availed himself of the counsel and advice of these experts and of the trade interests touching the products for which standards have been determined and has reached certain conclusions based on the general principles of examination and conduct hereinafter mentioned: $b$ Therefore, I, James Wilson, Secretary of Agriculture, do hereby proclaim and establish the following standards for purity of food products together with their precedent definitions as the official standards of these food products for the United States of America.

Washington, D. C., November 21, 1903.

JAMES Wilson.

\section{FOOD DEFINITIONS AND STANDARDS.}

\section{ANIMAL PRODUCTS.}

A. Meats and the Principal Meat Products.

a. MEATS.

Definitions.

1. Meat is any sound, dressed, and properly prepared edible part of animals in good health at the time of slaughter. The term "animals," as herein used, includes not only mammals, but fish, fowl, crustaceans, mollusks, and all other animals used as food.

2. Fresh meat is meat from animals recently slaughtered or preserved only by refrigeration.

3. Salted, pickled, and smoked meats are unmixed meats preserved by salt, sugar, vinegar, spices, or smoke, singly or in combination, whether in bulk or in packages.

\section{Standard.}

Standard meat, fresh meat, and salted, pickled, and smoked meats are such as conform respectively to the foregoing definitions.

\section{b. MANUfaCtured Meats.}

\section{Definition.}

1. Manufactured meats are meats not included in definitions 2 and 3 , whether simple or mixed, whole or comminuted, in bulk or packages, with or without the addition of salt, sugar, vinegar, spices, smoke, oils, or rendered fat. 


\section{Standard}

Standard manufactured meats conform to the foregoing definition. 'If they bear names descriptive of composition, they correspond thereto and when bearing such descriptive names, if force or flavoring meats are used, the kind and quantity thereof are made known.

$$
\text { c. MEAT EXtracts, MEAT peltones, htC. }
$$

(Schedule in preparation.)

$$
\text { d. LARD. }
$$

\section{Definitions.}

1. Lard is the rendered fresh fat from slaughtered, healthy hogs.

2. Leaf lard is the lard rendered at moderately high temperatures from the internal fat of the abdomen of the hog, excluding that adherent to the intestines.

\section{Standard.}

Standard lard and standard leaf lard are lard and leaf lard, respectively, free from rancidity, containing not more than one (1) per cent of substances other than fatty acids, not fat, necessarily incorporated therewith in the process of rendering; and standard leaf lard has an iodin number not greater than sixty (60).

\section{Definition.}

3. Neutral lard is lard rendered at low temperatures.

B. Milk. And Its Products.

a. MILKS.

\section{Definition.}

1. Milk (whole milk) is the lacteal secretion obtained by the complete milking of one or more healthy cows, properly fed and kept, excluding that obtained within fifteen days before and five days after calving.

\section{Standard.}

Standard milk is milk containing not less than twelve (12) per cent of total solids and not less than eight and one-half (8.5) per cent of solids not fat, nor less than three and one-quarter (3.25) per cent of milk fat.

\section{Definitions.}

2. Blended.milk is milk modified in its composition so as to have a definite and stated percentage of one or more of its constituents.

3. Skim milk is milk from which a part or all of the cream has been removed.

\section{Standard.}

Standard skim milk is skim milk containing not less than-nine and one-quarter (9.25) per cent of milk solids.

\section{Definitions.}

4. Buttermilk is the product that remains when butter is removed from milk or cream in the process of churning.

5. Pasteurized milk is standard milk that has been heated below boiling, but sufficiently to kill most of the active organisms present and immediately cooled to fifty degrees $\left(50^{\circ}\right)$ Fahr. or lower to retard the development of their spores. 
6. Sterilized milk is standard milk that has been heated at the temperature of boiling water-or higher for a length of time sufficient to kill all organisms present.

7. Condensed milk is milk from which a considerable portion of water has been evaporated.

8. Sweetened condensed milk is milk from which a considerable portion of water has been evaporated and to which sugar (sucrose) has been added.

\section{Standard.}

Standard condensed milk and standard sweetened condensed milk are condensed milk and sweetened condensed milk, respectively, containing not less than twenty-eight (28) per cent of milk solids, of which not less than one-fourth is milk fat.

\section{Definition.}

9. Condensed skim milk is skim milk from which a considerable portion of water has been evaporated.

\section{b. MILK FAT OR BUTTER FAT.}

\section{Definition.}

1. Milk fat or butter fat is the fat of milk.

\section{Standard.}

Standard milk fat or butter fat has a Reichert-Meissl number not less than twentyfour $(24)$, and a specific gravity not less than $0.905\left(40^{\circ} \mathrm{C} . / 40^{\circ} \mathrm{C}\right.$. $)$.

$$
\text { c. CREAM. }
$$

\section{Definition.}

1. Cream is that portion of milk, rich in butter fat, which rises to the surface of milk on standing, or is separated from it by centrifugal force.

\section{Standard.}

Standard cream is cream containing not less than eighteen (18) per cent of milk fat.

\section{Definition.}

2. Evaporated cream is cream from which a considerable portion of water has been evaporated.

\section{d. BUTTER.}

\section{Definition.}

1. Butter is the product obtained by gathering in any manner the fat of fresh or ripened milk or cream into a mass, which also contains a small portion of the other milk constituents, with or without salt. By acts of Congress approved August $2 \mathrm{~d}$, 1886, and May 9th, 1902, butter may also contain additional coloring matter.

\section{Standard.}

Standard butter is butter containing not less than eighty-two and five-tenths (82.5) per cent of butter fat.

\section{Definition.}

2. Renovated or process butter is the product obtained by melting butter and reworking, without the addition or use of chemicals or any substances except milk, cream, or salt. 


\section{Standard.}

Standard renovated or process butter is renovated or process butter containing not more than sixteen (16) per cent of water, and at least eighty-two and five-tenths (82.5) per cent of butter fat.
e. CHEESE.

\section{Definitions.}

1. Cheese is the solid and ripened product obtained by coagulating the casein of milk by means of rennet or acids, with or without the aldition of ripening ferments and seasoning. By act of Congress approved June 6, 1896, cheese may also contain additional coloring matter.

2. Whole milk or full-cream cheese is cheese made from milk from which no portion of the fat has been removed.

3. Skim-milk checse is cheese made from milk from which any portion of the fat has been removed.

4. Cream cheese is cheese made from milk and cream, or milk containing not less than six (6) per cent of fat.

\section{Standard.}

Standard whole-milk cheese or full-cream cheese is whole-milk or full-cream cheese containing in the water-free substance not less than fifty (50) per cent of butter fat.

f. Miscellaneous Milk pRoducts.

\section{Definition.}

1. Ice cream (In preparation).

Standard.

Standard ice cream (In preparation).

Definitions.

2. Whey is the product remaining after the removal of fat and casein from milk in the process of cheese making.

3. Kumiss is mare's or cow's milk, with or without the addition of sugar (sucrose), which has undergone alcoholic fermentation.

\section{VEGETABLE PRODUCTS.}

\section{A. Grain Products.}

(Schedule in preparation.)

\section{B. Fruits and Vegetables.}

(Schedule in preparation.)

C. Sugars and Related Substances.

a. SUGAR AND SUGAR PRODUCTS.

\section{Definition.}

1. Sugar is the product chemically known as sucrose (saccharose) chiefly obtained from sugar cane, sugar beets, sorghum, maple, or palm.

\section{Standard.}

Standard sugar is white sugar containing at least ninety-nine and five-tenths (99.5) per cert of sucrose. 


\section{Definitions.}

2. Granulated, loaf, cut, milled, and powdered sugars are different forms of standard sugars.

3. Maple sugar is the solid product resulting from the evaporation of maple sap.

4. Massecuite, melada, mush sugar, and concrete are products obtained by evaporating the purified juice of a sugar-producing plant, or a solution of sugar, to a solid or semisolid consistence in which the sugar chiefly exists in a crystalline state.

5. Molasses is the product.left after separating the sugar from massecuite, melada, mush sugar, or concrete.

\section{Standard.}

Standard molasses is molasses containing not more than twenty-five (25) per cent of water nor more than five (5) per cent of ash.

\section{Definitions.}

6. Sirup is the product obtained by purifying and evaporating the juice of a sugarproducing plant without removing any of the sugar.

7. Sugar-cane sirup is a sirup obtained by the evaporation of the juice of the sugar cane or by the solution of sugar-cane concrete.

8. Sorghum sirup is a sirup obtained by the evaporation of sorghum juice or by the solution of sorghum concrete.

9. Maple sirup is a sirup obtained by the evaporation of maple sap or by the solution of maple concrete.

10. Sugar sirup is a product obtained by dissolving sugar to the consistence of a sirup.

\section{Standard.}

Standard sirup is a sirup containing not more than thirty (30) per cent of water nor more than two and five-tenths (2.5) per cent of ash.

\section{b. GLUCOSE PRODUCTS.}

\section{Definition.}

1. Starch sugar or grape sugar is the solid product obtained by hydrolyzing starch or a starch-containing substance until the greater part of the starch is converted into dextrose. Starch sugar or grape sugar appears in commerce in two forms, anhydrous and hydrous. In the former the sugar is crystallized without water of crystallization; in the latter it is crystallized with water of crystallization. The hydrous varieties are commonly known as $70^{\circ}$ and 80 sugars; 70 sugar is also known as brewers' sugar, and 80 sugar as climax or acme sugar.

\section{Standards.}

(a) Standard 70 sugar or brewers' sugar is hyd̀rous starch sugar containing not less than seventy (70) per cent of dextrose and not more than eight-tenths (0.8) per cent of ash.

(b) Standard 80 sugar, climax or acme sugar, is hydrous starch sugar containing not less than eighty (80) per cent of dextrose and not more than one and one-half (1.5) per cent of ash.

(c) Standard anhydrous grape sugar is anhydrous grape sugar containing not less than ninety-five (95) per cent of dextrose without water of crystallization and not more than eight-tenths $(0.8)$ per cent of ash.

The ash of these standard products consists almost entirely of chlorids and sulphates of lime and soda. 


\section{Definition.}

2. Glucose, mixing glucose, or confectioners' glucose is a thick sirupy substance obtained by incompletely hydrolizing starch or a starch-containing substance, decolorizing and evaporating the product. It is found in various degrees of concentration, ranging from forty-one (41) to forty-five (45) degrees Baumé.

\section{Standard.}

Standard glucose, mixing glucose, or confectioners' glucose is colorless glucose, varying in density between forty-one (41) and forty-five (45) degrees Baumé, at a temperature of one hundred $(100)$ degrees $\mathrm{F}$. $\left(37.7^{\circ} \mathrm{C}\right.$.). It conforms in density, within these limits, to the degree Baume it is claimed to show, and for a density of fortyone (41) degrees Baumé contains not more than twenty-one (21) per cent of water and for a density of forty-five (45) degrees not mors than fourteen (14) per cent. It contains on a basis of forty-one (41) degrees Baumé not more than one (1) per cent of ash, consisting chiefly of chlorids and sulphates of lime and soda.

\section{Definition.}

3. Glucose sirup or corn simp is glucose unmixed or mixed with sirup or molasses.

\section{Standard.}

Standard glucose sirup or corn sirup is glucose sirup or corn sirup containing not more than twenty-five (25) per cent of water nor more than three (3) per cent of ash.

$$
\text { c. CANDY. }
$$

\section{Definition.}

1. Candy is a product prepared from a saccharine substance or substances, with or without the addition of harmless coloring, flavoring, or filling materials.

\section{Standard.}

Standard candy is candy containing no terra alba, barytes, talc, chrome yellow, or other mineral substances or poisonous colors or flavors or other ingredients injurious to health.

\section{d. HONEY.}

(Schedule in preparation.)

\section{Condiments (except vinegar).}

a. SPICES.

\section{General definition.}

1. Spices are aromatic vegetable substances used for the seasoning of food.

\section{General standard.}

Standard spices are sound spices, true to name, from which no portion of any volatile or other flavoring principle has been removed.

\section{Definition.}

2. Allspice or pimento is the dried fruit of Pimenta officianalis Lindl.

\section{Standard.}

Standard allspice is allspice containing not less than eight (8) per cent of quercitannic acid; $a$ not more than six (6) per cent of total ash; not more than five-tenths 
(0.5) per cent of ash insoluble in hydrochloric acid, and not more than twenty-five

(25) per cent of crude fiber.

\section{Definitions.}

3. Anise is the fruit of Pimpinella anisum L.

4. Bay leaf is the dried leaves of Laurus nobilis L.

5. Capers are the flower buds of Capparis spinosa $\mathrm{L}$.

6. Caraway is the fruit of Carum carvi $\mathbf{L}$.

\section{CAYENNE AND RED PEPPERS.}

7. Red pepper is the red, dried, ripe fruit of any species of Capsicum.

8. Cayenne pepper, or cayenne, is the dried, ripe fruit of Capsicum fastigiatum DC., Capsicum frutescens L., Capsicum baccatum L., or some other small-fruited species of Capsicum.

\section{Standard.}

Standard cayenne pepper is cayenne pepper containing not less than fifteen (15) per cent of nonvolatile ether extract, not more than six and five-tenths (6.5) per cent of total ash, not more than five-tenths (0.5) per cent of ash insoluble in hydrochloric acid, not more than one and five-tenths (1.5) per cent of starch by the diastase method, and not more than twenty-eight (28) per cent of crude fiber.

\section{Definitions.}

9. Celery seed is the dried seed of Apium graveolens $\mathrm{L}$.

10. Cinnamon is the dried bark of any species of the genus Cinnamomum, from which the outer layers may or may not have been removed.

11. True cinnamon is the dried inner bark of Cinnamomum zeylanicum Breyne.

12. Cassia is the dried bark of various species of Cinnamomum, other than Cinnamomum zeylanicum, from which the outer layers may or may not have been removed.

13. Cassia buds are the dried immature fruit of species of Cinnamomum.

14. Ground cinnamon, or ground cassia, is a powder consisting of cinnamon, cassia, or cassia buds, or a mixture of these spices.

\section{Standard.}

Standard cinnamon or cassia is cinnamon or cassia containing not more than eight (8) per cent of total ash and not more than two (2) per cent of sand.

\section{Definition.}

15. Cloves are the dried flower buds of Eugenia caryophyllata Thunb. (Caryophyllus aromaticus L.), which contain not more than five (5) per cent of clove stems.

\section{Standard.}

Standard cloves are cloves containing not less than ten (10) per cent of volatile ether extract, not less than twelve (12) per cent of quercitannic acid, ${ }^{a}$ not more than eight (8) per cent of total ash, not more than five-tenths (0.5) per cent of ash insoluble in hydrochloric acid, and not more than ten (10) per cent of crude fiber.

\section{Definitions.}

16. Coriander is the dried fruit of Coriandrum sativum L.

17. Cumin seed is the fruit of Cuminum cyminum $\mathrm{L}$.

18. Dill seed is the fruit of Peucedanum graveolenis Benth. \& Hook. 
19. Fennel is the fruit of Foniculum vulgare Gaertı.

20. Ginger is the washed and dried, or decorticated and dried, rhizome of Zingiber officinale Roscoe.

\section{Standard.}

Standard ginger is ground or whole ginger containing not less than forty-two (42) per cent of starch by the diastase method nor less than forty-six (46) per cent by direct inversion, $a$ not more than eight (8) per cent of crude fiber, not more than eight (8) per cent of total ash, not more than one (1) per cent of lime, and not more than three (3) per cent of ash insoluble in hydrochloric acid.

\section{Definition.}

21. Limed or bleached ginger is whole ginger coated with carbonate of lime.

\section{Standard.}

Standard limed or bleached ginger is limed or bleached ginger containing not more than ten (10) per cent of ash, not more than four (4) per cent of carbonate of lime, and conforming in other respects to standard ginger.

\section{Definition.}

22. Horse-radish is the root cf Cochlearia armoracia $\mathrm{L}$.

\section{Standard.}

Standard grated or ground horse-radish may be mixed with vinegar.

\section{Definition.}

23. Mace is the dried arillus of Myristica fragrans Houttuyn.

\section{Standard.}

Standard mcce is mace containing not less than twenty (20) nor more than thirty (30) per cent of nonvolatile ether extract, not more than three (3) per cent of total ash, not more than five-tenths $(0.5)$ per cent of ash insoluble in hydrochloric acid, and not more than ten (10) per cent of crude fiber.

\section{Definitions.}

24. Macassar or Papua mace is the dried arillus of Myristica argentea Warb.

25. Bombay mace is the dried arillus of Myristica malabarica Lamarck.

26. Marjoram is the leaves, flowers, and branches of Origanum majorana L.

27. Mustard seed is the seed of Sinapis alba L. (white mustard), Brassica nigra (L.) Koch (black mustard), or Brassica juncea (L.) Coss. (East Indian mustard).

28. Ground mustard is a powder made from mustard seed, with or without the removal of the hulls and a portion of the fixed oil.

\section{Standard.}

Standard ground mustard is mustard containing not more than two and five-tenths (2.5) per cent of starch by the diastase method and not more than eight (8) per cent of total ash.

\section{Definition.}

29. Nutmeg is the dried seed of Myristica fragrans Houttuyn, deprived of its testa and with or without a thin coating of lime. 
Standard.

Standard nutmegs, ground or unground, are nutmegs containing not less than twenty-five (25) per cent of nonvolatile ether extract, not more than five (5) per cent of total ash, not more than five-tenths $(0.5)$ per cent of ash insoluble in hydrochloric acid, and not more than ten (10) per cent of crude fiber.

\section{Definitions.}

30. Macassar, Papua, male, or long nutmeg is the dried seed of Myristica argentea Warb., deprived of its testa.

31. Paprica is the dried ripe fruit of Capsicum annuum L., Capsicum longum DC., or some other large-fruited species of Capsicum.

\section{PEPPER.}

32. Black pepper is the dried immature berries of Piper nigrum $\mathrm{L}$.

\section{Standard.}

Standard black pepper is black pepper free from added pepper shells, pepper dust, and other pepper by-products and containing not less than six (6) per cent of nonvolatile ether extract; not less thar twenty-two (22) per cent of starch by the diastase method; not less than twenty-eight (28) per cent-of starch by direct inversion, ${ }^{a}$ not more than seven (7) per cent of total ash; not more than two (2) per cent of ash insoluble in hydrochloric acid, and not more than fifteen (15) per cent of crude fiber. One hundred parts of the nonvolatile ether extract contain not less than three and one quarter (3.25) parts of nitrogen.

\section{Definitions.}

33. Long pepper is the dried fruit of Piper longum $\mathrm{L}$.

34. White pepper is the dried mature berries of Piper nigrum L., from which the outer coating, or the outer and inner coatings, have been removed.

\section{Standard.}

Standard white pepper is white pepper containing not less than six (6) per cent of nonvolatile ether extract; not less than forty (40) per cent of starch by the diastase method; not less than fifty-three (53) per cent of starch by direct inversion; $a$ not more than four (4) per cent of total ash; not more than five-tenths (0.5) per cent of ash insoluble in hydrochloric acid, and not more than five (5) per cent of crude fiber. One hundred parts of the nonvolatile ether extract contain not less than (4) parts of nitrogen.

\section{Definitions.}

35. Saffron is the dried stigmas of Crocus sativus L.

36. Sage is the leaves of Salvia officinalis L.

37. Savory, or summer savory is the leaves, blossoms, and branches of Satureia hortensis $\mathrm{L}$.

38. Thyme is the leaves and ends of blooming branches of Thymus vulgaris $\mathrm{L}$.

$$
\text { b. FRUIT EXTRACTS. }
$$

(Schedule in preparation.)

c. SALAD OILS.

(Schedule in preparation.) 
d. SALT.

(Schedule in preparation.)

E. Beverages (ani) vinegar).

a. TEA.

(Schedule in preparation.)

b. COFFFE.

(Schedule in preparation).

c. COCOA AND COCOA PRODUCTS.

\section{Definitions.}

1. Cocoa beans are the seeds of the cacao tree, Theobroma cacuo L.

2. Cocoa nibs, or cracked cocoa is the roasted, broken cocoa bean freed from its shell or husk.

3. Chocolate, plain or bitter, or chocolate liquor, is the solid or plastic mass obtained by grinding cocoa nibs without the removal of fat or other constituents except the germ.

\section{Standard.}

Standard chocolate is chocolate containing not more than three (3) per cent of ash insoluble in water, three and fifty hundredths (3.50) per cent of crude fiber and nine (9) per cent of starch, nor less than forty-five (45) per cent of cocoa fat.

\section{Definition.}

4. Sweet chocolate and chocolate coatings are plain chocolate mixéd with sugar (sucrose), with or without the addition of cocoa butter, spices, or other flavoring materials.

\section{Standard.}

Standard sweet chocolate and standard chocolate coating are sweet chocolate and chocolate coating containing in the sugar-free and fat-free residue no higher percentage of either ash, fiber, or starch than is found in the sugar-free and fat-free residue of plain chocolate.

\section{Definition.}

5. Cocoa or powdered cocoa is cocoa nibs, with or without the germ, deprived of a portion of its fat and finely pulverized.

\section{Standard.}

Standard cocoa is cocoa containing percentages of ash, crude fiber, and starch corresponding to those in chocolate after correction for fat removed.

\section{Definition.}

6. Sweet or sweetened cocoa is cocoa mixed with sugar (sucrose).

Standard.

Standard sucet cocoa is sweet cocoa containing not more than sixty (60) per cent of sugar (sucrose) and in the sugar-free and fat-free residue no higher percentage of either ash, crude fiber or starch than is found in the sugar-free and fat-free residue of plain chocolate.

d. FRUIT JUICES-FRESH, SWEET, ANI FERMENTED.

(In preparation.) 
e. VINEGAR.

(In preparation.)

f. MEAD, ROOT BEER, ETC.

(In preparation.)

g. MALT LiquORS.

(In preparation.)

h. SPIRITUOUS LIQUORS.

(In preparation.)

i. carbonated waters, etc.

III. PRESERVATIVES AND COLORING MATTERS.

(In preparation.)

O 
. 


\section{RETURN CIRCULATION DEPARTMENT}

TO $\rightarrow 202$ Main Library

\begin{tabular}{l|l|l}
\hline $\begin{array}{c}\text { LOAN PERIOD 1 } \\
\text { HOME USE }\end{array}$ & 2 & 3 \\
\hline 4 & 5 & 6 \\
\hline
\end{tabular}

ALL BOOKS MAY BE RECALLED AFTER 7 DAYS

Renewals and Recharges may be made 4 days prior to the due date.

Books may be Renewed by calling $642-3405$.

\section{DUE AS STAMPED BELOW}

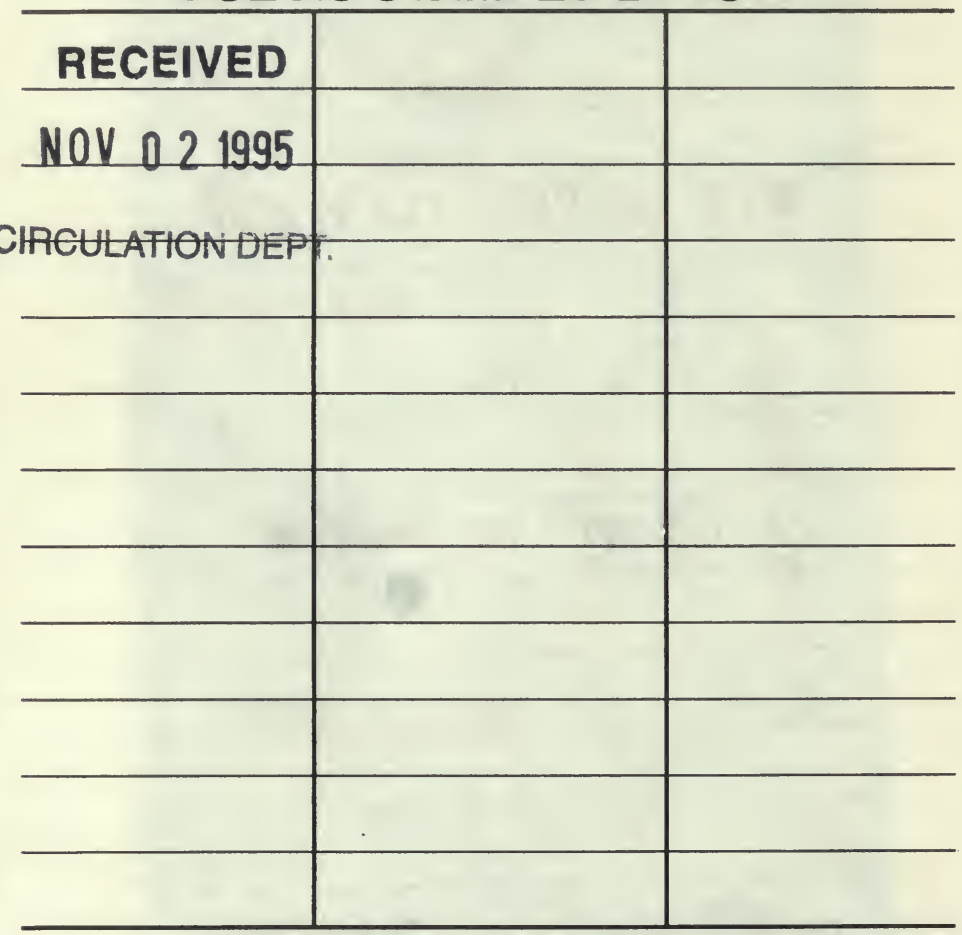

UNIVERSITY OF CALIFORNIA, BERKELEY

FORM NO. DD6

BERKELEY, CA 94720 
U. C. BERKELEY LIBRARIES |||||||| ||| || || || || | C051402926

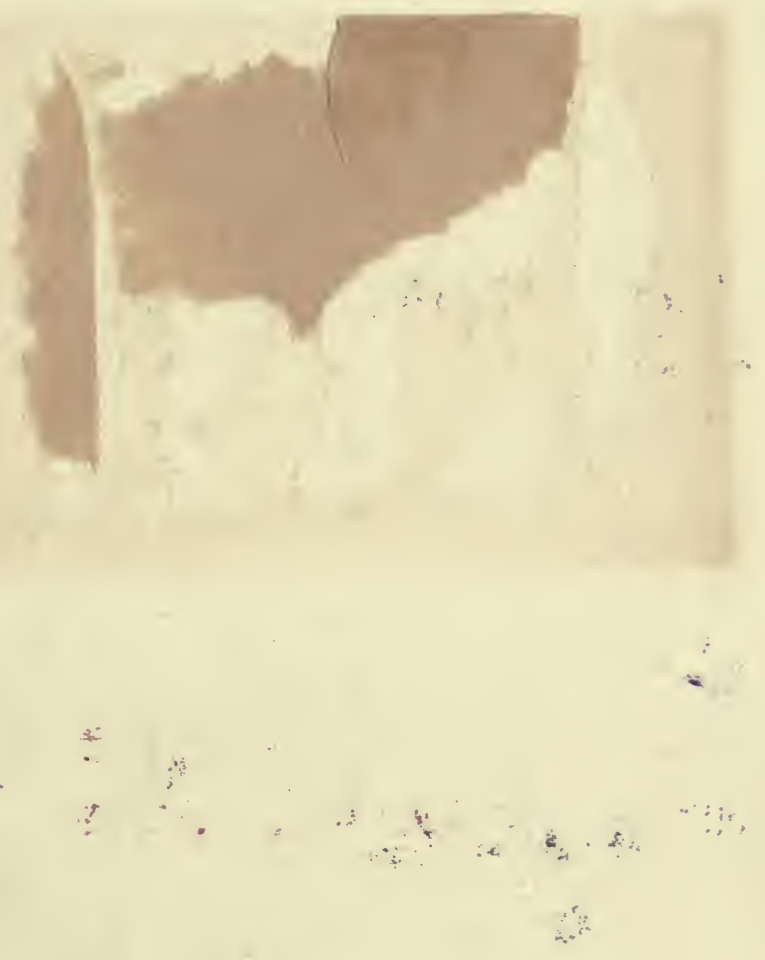




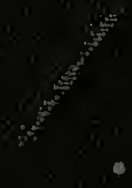

